\title{
Population Screening for Colorectal Cancer: Advantages and Drawbacks
}

\author{
Ole Kronborg $^{a} \quad$ Jaroslaw Regula ${ }^{b}$ \\ a Department of Surgery A, Odense University Hospital, Odense, Denmark; ${ }^{b}$ Department of Gastroenterology, \\ Medical Centre for Postgraduate Education and Institute of Oncology, Warsaw, Poland
}

\begin{abstract}
Key Words
Colorectal cancer, screening • Population screening, advantages and drawbacks - Fecal occult blood tests . Fecal DNA • Flexible sigmoidoscopy · Colonoscopy • Double contrast barium enema $\cdot$ Computed tomographic colonoscopy
\end{abstract}

\begin{abstract}
Screening for colorectal cancer (CRC) has been shown to reduce mortality from the disease as well as incidence. Several methods for screening are available, but none are ideal. The present short review discusses the advantages and drawbacks using fecal occult blood tests (FOBTs), fecal DNA tests, flexible sigmoidoscopy (FS), colonoscopy, double contrast barium enema, and computed tomographic colonoscopy. The use of FOBTs with following colonoscopy in persons with a positive test has been shown to reduce mortality as well as the incidence of CRC in several randomized trials. It is likely that other methods will do the same, but it is not clear how large the benefit will be. Repeated testing is necessary for FOBTs and DNA tests as well as FS, and a high degree of acceptability is crucial for the effectivity of all tests in a national program. National services may be subject to variations in enthusiasm and expertise, resulting in varying acceptability and number of complications. It is recom-
\end{abstract}

(C) 2007 S. Karger AG, Basel

0257-2753/07/0253-0270\$23.50/0

Fax +4161306 1234

E-Mail karger@karger.ch

www.karger.com
Accessible online at: www.karger.com/ddi mended to perform pilot studies in limited populations (as in the UK) before embarking on a screening program on a national level.

Copyright $\odot 2007$ S. Karger AG, Basel

\section{Advantages}

Fecal Occult Blood Tests

Detection of occult blood in stools using guaiac tests is the only method proven to reduce mortality and incidence of colorectal cancer (CRC) in three large-scale, long-term, randomized trials [1-4]. The trials in Funen and Nottingham using biennial unrehydrated fecal occult blood tests found 18 and 15\% mortality reduction, respectively. The Minnesota trial using both rehydrated and unrehydrated tests found mortality reduction of $18 \%$ in the biennially screened group and $33 \%$ in the annually screened group. The rehydration causes higher positivity and one third of screened persons underwent colonoscopy in the Minnesota trial and this factor is the most probable explanation for the highest mortality reduction in that trial. Although the sensitivity of a single test is relatively low, an annual testing program detects more than $90 \%$ of cancers. A single test is cheapest of all, easy to perform even at home, and acceptable. The use of new- 
er immunochemical tests does not require dietary restrictions and makes that type of testing even more acceptable. These tests are more sensitive to cancer and more expensive than guaiac-based tests.

\section{Fecal DNA}

Fecal DNA testing using a panel of 21 mutations in a screening setting [5] had a significantly higher sensitivity than Hemoccult ${ }^{\circledR}$ testing in the detection of invasive cancer (51.6 vs. $12.9 \%$ ) and invasive cancers plus high-grade dysplasia adenomas (40.8 vs. 14.1\%). Advanced neoplasia also tended to be detected more often (18.2 vs. $10.8 \%)$, but the difference was not statistically significant. Sensitivity was the same. Further improvements consisting of better preservation of stool DNA during transportation and processing as well as reduction of number of mutations screened will probably make this testing a very attractive alternative to occult blood testing.

\section{Flexible Sigmoidoscopy}

Good evidence from case-control studies has shown CRC mortality reduction especially from lesions located within the reach of sigmoidoscopy [6-8]. The protective effect lasts for about 10 years after the last screening procedure. Finding lesions during sigmoidoscopy implies usually performing full colonoscopy to ensure that proximal lesions are absent. A special index based on sigmoidoscopy result, age and gender has been proposed. The policy of performing total colonoscopy after positive sigmoidoscopy has led to an $80 \%$ reduction of CRC incidence [9]. Results of a British randomized trial are awaited. Sigmoidoscopy can be performed by non-physician personnel, is less time-consuming than colonoscopy, usually does not require sedation, and may be performed after simple bowel preparation.

\section{Colonoscopy}

Colonoscopy is the best single diagnostic tool allowing for detection and biopsy of cancers, including early, flat lesions and removal of polyps in the whole large bowel. Colonoscopy with endoscopic removal of all detected polyps was shown to reduce CRC incidence [10]. As a screening method it may be safely repeated at as long as 10 -year intervals. It is also the only one-stage screening method, as opposed to all other modalities that are regarded as a two-stage operation (initial test followed by colonoscopy in case of positivity). The colonoscopy approach makes screening organization much easier as compared to all other two-stage policies. Prospective colonoscopic studies have shown that half of the patients with proximal advanced neoplasia had no lesions distal to the splenic flexure and therefore these lesions would have been missed if only sigmoidoscopy had been performed [11-13]. This was mostly evident in women [14]. Large, national-scale colonoscopic programs are feasible, with a $91 \%$ cecal intubation rate and low complication rate as shown in a recent study [15]. Currently, most patients and gastroenterologists prefer the option of direct colonoscopic screening.

\section{Double Contrast Barium Enema}

This method which is still largely available is usually regarded as an option for screening those persons in whom it is the only possible method of examining the whole large bowel. It detects cancers and large polyps with sufficient sensitivity. A single case-control study showed a 33\% percent reduction of CRC deaths [16].

\section{Computed Tomographic Colonoscopy}

The virtual colonoscopy using CT or magnetic resonance technology is characterized by a wide variation of sensitivity for large polyps from 40 to $95 \%$. Technology improvements and especially the possibility of stool-tagging (thus avoiding the need of bowel preparation) will probably make this test a good alternative for initial screening testing. An important additional advantage is the ability to detect extracolonic disease at a rate of about $10 \%$. In case of detecting clinically important abnormalities, this method will induce further follow-up or therapy.

\section{Drawbacks}

\section{Fecal Occult Blood Tests}

The sensitivity for detection of CRC in programs with biennial screening from the age of $45-50$ years is no more than $60 \%$ using the conventional guaiac test Hemoccult$\mathrm{II}^{\circledR}$ with two samples from each of three defecations [17]. Increasing the sensitivity by rehydration of the slides or use of the HemeSensa test reduces specificity, and the number of non-beneficial colonoscopies is thereby increased. The predictive value for detection of CRC is reduced from 12 to $2 \%$ by rehydration [17]. The sensitivity for significant adenomas (at least $1 \mathrm{~cm}$, multiple, villous, severe dysplasia) is lower than $50 \%$ for Hemoccult-II. The specificity may be increased by dietary restrictions during 3 days before sampling, but the acceptability will then decrease below the $60 \%$ seen in major population trials. The guaiac tests are observer-dependent and should therefore be analyzed in laboratories doing many tests 
within a small number of technicians. In contrast, immunochemical tests, specific for human hemoglobin, may be analyzed mechanically, but they are more expensive and the specificity may be less than that of guaiac tests. However, it may be possible to reduce the number of colonoscopies needed by use of the two-tier approach, performing immunochemical tests in persons with week positive guaiac tests, without decrease in specificity [18], but this may cause further inconvenience to the persons tested. Repeated testing every 1-2 years is necessary and the sensitivity of the program is dependent on acceptability of the fecal occult blood tests as well as the colonoscopy in those with positive test. Educational efforts are necessary to overcome the perils of prudishness by fecal sampling, and the procedure itself may be simplified in several ways. So-called interval cases (CRC being diagnosed between screening rounds) may be considered failures of screening, but the cancer-specific survival is better than that of controls having no screening in randomized trials [17].

\section{Fecal DNA}

It is a major drawback that multiple DNA changes must be looked for and each marker must be specific [19]. Screening for Ki-ras and p53 alone has resulted in sensitivities that are no better than that of Hemoccult-II. The methods are labor-intensive and expensive, and it is not known whether they will improve efficacy of screening. A recent study using a 21-DNA mutation panel only showed a sensitivity of $41 \%$ for CRC or adenomas with severe dysplasia compared with colonoscopy [20].

\section{Flexible Sigmoidoscopy}

The examination covers no more than $50 \%$ of the area where CRC is found, because the complete sigmoid colon is seen in only $75 \%$ of persons having flexible sigmoidoscopy (FS) [20]. No more than $25 \%$ of more orally placed cancers may be found indirectly by colonoscopy as indi-

cialists. Bowel preparation is necessary as well as air insufflation during the examination. Sedation is needed in most cases and the acceptability is probably low, but no results are available from representative samples of the general population with an average risk of CRC. Colonoscopy is expensive and priority for screening may result in less resources being available for symptomatic patients. It has been estimated that CRC would be found in $1 \%$ of colonoscopies in persons 50-75 years of age [20].

\section{Double Contrast Barium Enema}

Sensitivity and specificity are probably lower than that of colonoscopy and the examination is observer-dependent. It has not been evaluated as a screening procedure and in spite of being less expensive than colonoscopy, it is unpleasant because of necessary bowel preparation and air insufflation. Double contrast barium enema carries a small risk from irradiation, and removal of polyps is not possible.

\section{Computed Tomographic Colonoscopy}

The examination carries similar drawbacks as double contrast barium enema and is more expensive. However, the risk from irradiation may be eliminated by using a MR instead of a CT technique. It has not been evaluated for population screening purposes. Overall, it should be remembered that screening for CRC carries the same adverse effects as screening for other malignant diseases, i.e. physical and psychological morbidity, 'certificate of health' effect, cost and effect on symptomatic service. A national service may be subject to variations in levels of enthusiasm and expertise, and the level of compliance obtained by the efforts of dedicated researchers may be difficult to replicate in nationwide programs. cated by distal neoplasia [17]. The acceptability has most often been below $50 \%$. FS is unpleasant and a bowel preparation is necessary. Repeated examination is probably needed with intervals of a few years, but no results are available yet from large randomized trials. The FS carries a small risk of perforation which increases when doing polypectomy. It is moderate expensive.

\section{Colonoscopy}

The examination is invasive and endoscopist-dependent, the cecal intubation rate being $80-95 \%$. There is a risk of perforation of $0.2-2.0 \%$ and a major need of spe-

\section{References}

$\checkmark 1$ Mandel JS, Bond JH, Church TR, et al: Reducing mortality from colorectal cancer by screening for fecal occult blood. Minnesota Colon Cancer Control Study. N Engl J Med 1993;328:1365-1371.

-2 Hardcastle JD, Chamberlain JO, Robinson $\mathrm{MH}$, et al: Randomised controlled trial of faecal-occult-blood screening for colorectal cancer. Lancet 1996;348:1472-1477.

3 Kronborg O, Fenger C, Olsen J, et al: Randomised study of screening for colorectal cancer with faecal-occult-blood test. Lancet 1996;348:1467-1471

4 Mandel JS, Church TR, Bond JH, et al: The effect of fecal occult-blood screening on the incidence of colorectal cancer. N Engl J Med 2000;343:1603-1607. 
5 Imperiale TF, Ransohoff DF, Itzkowitz SH, et al: Fecal DNA versus fecal occult blood for colorectal-cancer screening in an averagerisk population. N Engl J Med 2004;351: 2704-2714.

-6 Selby JV, Friedman GD, Quesenberry CR Weiss NS: A case-control study of screening sigmoidoscopy and mortality from colorectal cancer. N Engl J Med 1992;326:653-657.

7 Newcomb PA, Norfleet RG, Storer BE, Surawicz T, Marcus PM: Screening sigmoidoscopy and colorectal cancer mortality. J Natl Cancer Inst 1992;84:1572-1575.

$>8$ Kavanagh AM, Giovanucci EL, Fuchs CS, Colditz GA: Screening endoscopy and risk of colorectal cancer in US men. Cancer Causes Control 1998;9:455-462.

$>9$ Thiis-Evensen E, Hoff GS, Sauer J, Langmark F, et al: Population-based surveillance by colonoscopy: effect on the incidence of colorectal cancer. Scand J Gastroenterol 1999;34:414-420.
10 Winawer SJ, Zauber AG, Ho MN, et al: Prevention of colorectal cancer by colonoscopic polypectomy. The National Polyp Study Workgroup. N Engl J Med 1993;329:19771981.

11 Lieberman DA, Weiss DG, Bond JH, et al: Use of colonoscopy to screen asymptomatic adults for colorectal cancer. N Engl J Med 2000;343:162-168.

12 Imperiale TF, Wagner DR, Lin CY, et al: Risk of advanced proximal neoplasms in asymptomatic adults according to the distal colorectal findings. N Engl J Med 2000;343: 169-174.

13 Strul H, Kariv R, Leshno M, et al: The prevalence rate and anatomic location of colorectal adenoma and cancer detected by colonoscopy in average-risk individuals aged 40-80 years. Am J Gastroenterol 2006;101:255262.

14 Schoenfeld P, Cash B, Flood A, et al: Colonoscopic screening of average-risk women for colorectal neoplasia. N Engl J Med 2005;352: 2061-2068.

15 Regula J, Rupinski M, Kraszewska E, et al: Colonoscopy in colorectal-cancer screening for detection of advanced neoplasia. N Engl J Med 2006;355:1863-1872.
16 Scheitel SM, Ahlquist DA, Wollan PC, et al: Colorectal cancer screening: a community case-control study of proctosigmoidoscopy, barium enema radiography, and fecal occult blood test efficacy. Mayo Clin Proc 1999;74: 1207-1213.

17 Hakama M, Hoff G, Kronborg O, Påhlman L: Screening for colorectal cancer. Acta Oncologica 2005;44:425-439.

18 Fraser CG, Matthew CM, Mowat NAG, Wilson JA, Carey FA, Steele RJC: Immunochemical testing of individuals positive for guaiac faecal occult blood test in a screening programme for colorectal cancer: an observational study. Lancet Oncol 2006;7:127-131.

19 Kronborg O: Screening for colorectal cancer in the average-risk population. Semin Colon Rect Surg 2002;13:16-30.

20 Nicholson FB, Barro JL, Atkin W, Lilford R, Patrick J, Williams CB, Pignone M, Steele R, Kamm MA: Review article: population screening for colorectal cancer. Aliment Pharmacol Ther 2005;22:1069-1077. 